Geopolítica(s) Revista de estudios sobre espacio y poder ISSN: 2172-3958

https://dx.doi.org/10.5209/geop.72013

\title{
La revancha de la Historia
}

Bruno Tertrais (2017) La revanche de l'Histoire. París: Odile Jacob, 140 pp. ISBN: 978-2738136992.

Tertrais acaba de publicar su último libro, La revanche de l'Histoire, en la editorial Odile Jacob. En la introducción, el autor parte de la constatación de que, "pocas veces, el pasado ha estado tan presente. Jamás en la época moderna, ha tenido tanta importancia en las relaciones internacionales y en el escenario geopolítico" (p.12). En un mundo supuestamente sin memoria, la Historia irrumpe con fuerza por todas partes. Así, "Daech quiere instaurar el califato y [hacer desaparecer] las fronteras coloniales. Turquía e Irán se inspiran en su pasado imperial. China justifica sus derechos sobre las islas adyacentes a su territorio a través de mapas antiguos. Rusia anexiona el lugar de su presunto bautizo. Hungría otorga pasaportes a los antiguos sujetos del Imperio", etc. (p.12). En la era del repliegue nacional y del yihad global, el pasado "es exhumado, reconstruido, reinventado [y] mitificado para servir de inspiración o de repulsivo, de justificación de las reivindicaciones, de guía para la acción [y] de referencia para la [comprensión] de las situaciones" (pp.12-13).

Se exaltan las grandes victorias y se conmemoran las derrotas. "Se legisla [y] se reforma la Constitución para referirse a la Historia. Se restaura, se [ordenan] excavaciones arqueológicas, se exige la repatriación de objetos antiguos. Se abren museos y memoriales o, al contrario, se destruyen símbolos del pasado. Se reescriben los libros de texto, se ruedan películas y videoclips propagandísticos, se renombran ciudades y provincias" (p.13). En ese sentido, se asiste a la venganza del pasado. "Frente a las promesas de un futuro radioso, encarnado por el liberalismo y el socialismo, y contra la dilución de las identidades y la disolución de las raíces en el gran baño de la globalización, el nacionalismo y el islamismo proponen remedios basados en la tradición e incluso en la vuelta a una supuesta edad de oro" (p.13). El fenómeno se amplifica con "la proliferación de los Estados, y la emergencia de nuevas potencias [provoca] una necesidad de anclaje en un pasado real o imaginario" (p.13). Ambos fenómenos están vinculados entre sí, puesto que, "cuando la Historia empieza de nuevo, el pasado sale a la superficie" (p.13).

En efecto, "hemos entrado en un mundo en el cual la función esencial de la memoria colectiva es legitimar una cierta visión del mundo, un proyecto político y social, y deslegitimar las de los oponentes políticos"1. La novedad del periodo ac-

1 D. Rieff: In Praise of Forgetting. Historical Memory and Its Ironies. New Haven: Yale University Press, 2016. 
tual estriba en que las ideologías dominantes, que son el nacionalismo y el islamismo, son las que más ancladas están en el pasado (p.14). De hecho, "los grandes desafíos estratégicos del mundo contemporáneo se basan en reivindicaciones históricas profundas" (p.14). Y, las principales regiones del planeta están, cada una a su manera y de forma simultánea, afectadas por este fenómeno (p.14).

En el primer capítulo, titulado "Cuando la Historia recomienza, el pasado sale a la superficie", el autor observa que, debatida en el momento de la caída del Muro de Berlín, la idea de "fin de la Historia" carece de sentido hoy en día, ya que las refutaciones son innumerables (p.17). El autor de esa frase, Francis Fukuyama ${ }^{2}$, afirmaba que "el debate sobre la forma óptima de gobierno estaba clausurado. (...) La democracia liberal y la economía de mercado [serían] las únicas opciones viables para las sociedades modernas" (p.18). Diez años más tarde, a pesar de la competencia de modelos alternativos, Fukuyama ${ }^{3}$ mantenía su análisis en un artículo publicado en The Washington Post, al considerar que la democracia liberal acabaría triunfando, al ser únicamente una cuestión de tiempo.

El otro gran relato de los años noventa del pasado siglo es el del "choque de las civilizaciones", título de una obra de Samuel Huntington ${ }^{4}$, que ofrece una parrilla de lectura diferente. Independientemente de la pertinencia de las tesis avanzadas por el politólogo norteamericano, lo cierto es que algunos actores clave a nivel internacional perciben el mundo actual de esta forma. Para ellos, "el yihadismo [radical] lleva a cabo una guerra de civilización contra Occidente" (p.19). Para Tertrais, esta perspectiva es a la vez discutible, insuficiente e incoherente (p.20).

A pesar de privilegiar enfoques diferentes, las problematizaciones de Fukuyama y Huntington coinciden con ciertos discursos apocalípticos contemporáneos, tanto en Rusia y Estados Unidos como en países de confesión musulmana. Esa supuesta lucha del Bien contra el Mal ofrece una visión simplificada, clara y fácilmente comprensible de los acontecimientos históricos (p.20). Ambos discursos se nutren mutuamente (p.21).

En todo caso, "simplificar los fenómenos políticos complejos es una solución a menudo cómoda para abstenerse de pensar o de actuar" (p.24). En semejante contexto, cierta Historia es susceptible de ofrecer un esquema explicativo simple. Así, en un Oriente Medio complejo, algunas ideas simples se imponen, ideas según las cuales, desde tiempos inmemoriales, asistiríamos a un enfrentamiento entre suníes y chííes o entre árabes y persas (p.24). De la misma forma, "la idea de un traumatismo fundador es una parrilla de lectura popular, que se trate de la colonización, del desmembramiento de los imperios, de la partición, del éxodo, de la derrota militar, de la intervención externa o (...) del genocidio" (p.25). Si estos traumas son reales y referirse a ellos es legítimo, dan a veces lugar a comportamientos victimarios (p.25). Y, como lo subraya el autor, "del traumatismo a la humillación solo hay un paso" (p.25), sabiendo que "la humillación histórica se ha convertido en una explicación creciente de las relaciones internacionales" (p.25). Otra forma de dar cuenta del mundo a través de la Historia "consiste en recurrir a la analogía, bajo la forma de una comparación o de una metáfora" (p.26). El supuesto retorno a

F. Fukuyama: The end of History? The National Interest, (16), 1989, 3-18.

F. Fukuyama: They can only go so far. The Washington Post, 24 de agosto de 2008.

S. Huntington: The Clash of Civilizations a d the Remaking of World Order. New York: Simon \& Schuster, 1996. 
la Edad Media es una de ellas. Es asociada al debilitamiento de la soberanía, a un mundo sin reglas y a la vuelta de la barbarie (p.26).

De todas formas, "la Historia es una fuente de motivación para los pueblos y un instrumento de legitimación y de movilización para los dirigentes" (p.27). Esto sucede especialmente en los regímenes autoritarios (p.27). Así, "el hitlerismo intentó enraizarse en una cultura germánica mitificada y heroica" (p.27). Si ese fenómeno ha sido una constante a lo largo de la historia, jamás ha sido tan extendido. "Se recuerda el destino nacional, se descubre de nuevo un pasado mitificado, al que [nos] vincula un lazo más o menos tenue, para proyectarnos en el futuro" (p.27). En esa óptica, "la Historia sirve de modelo para la obra de restauración de la harmonía del pasado" y se conmemoran acontecimientos pasados considerados como "fundadores y ejemplares" (p.28). Esto da lugar a un amontonamiento de estratos históricos que acaban confundiéndose (p.28) en "una visión romántica del pasado" (p.29). Así recreado e instrumentalizado, "el pasado sale de la memoria muerta para entrar en la memoria viva" (p.29). Al contrario, el pasado puede ser utilizado como un precedente trágico que conviene no repetir. A su vez, para evitar volver a los enfrentamientos, divisiones e injerencias externas, se utiliza la analogía histórica que constituye "una de las más poderosas armas políticas" (p.29); siendo conscientes de que las tragedias del siglo XX son una fuente inagotable de metáforas: Diktat, pandemia, depresión, etc. (p.30).

Por último, "el pasado puede ser un peso a llevar y, a veces, a eliminar, [ya que] los precedentes históricos pueden crear una [tendencia] que conviene asumir o, al contrario, corregir" (p.31). En las democracias, "el peso de las faltas pasadas debe ser llevado y transmitido a las futuras generaciones [en el marco de una] cultura del arrepentimiento" (p.31). Tienden a asumirlo o a exhumarlo en lugar de intentar borrarlo y eliminarlo, aunque la damnatio memoriae siga practicándose (p.33). A la inversa, puede existir la tentación de eliminar el pasado. De hecho, "desde la Antigüedad, el conquistador intenta borrar las huellas de sus predecesores" (p.31). Ha sido el caso de la revolución kemalista en Turquía que ha hecho desaparecer cualquier referencia al pasado otomano (p.32). Para los totalitarismos, la ocultación del pasado no es solamente el lanzamiento de una nueva era, sino que es igualmente el momento de la destrucción y de la reescritura del pasado (p.32).

En el segundo capítulo, consagrado a las raíces de la revancha de la Historia, el autor constata que, a medida que el porvenir radioso deja lugar a las dificultades del presente, en los ámbitos políticos, económicos y socioculturales, y que se manifiesta la necesidad de un anclaje identitario, "el deseo de amarrarse a un pasado, aunque fuera mítico, se hace cada vez más fuerte" (p.35). Las raíces de esta revancha son numerosas y no dejan de profundizarse hasta generar un profundo malestar en las sociedades contemporáneas (p.35).

De hecho, se produce una doble desilusión:

Por una parte, sobre un eje temporal, las decepciones provocadas por los errores o los abusos del progresismo, bajo su forma liberal o marxista. Por otra parte, sobre un eje espacial, el enfado y el rechazo [que generan] los desajustes producidos por la globalización, a la obra tanto en los países occidentales como en los países emergentes bajo la forma de una reacción contra la occidentalización (p.36). 
Esto traduce la desconfianza existente actualmente hacia la modernidad y el progreso (p.36). Esa desconfianza "conoce hoy en día un incuestionable [auge]. Porque si la Historia se acelera desde el inicio de los tiempos modernos, [lo hace actualmente] de manera vertiginosa, especialmente desde el final de los años 1970" (p.36). En efecto, desde entonces, la Historia se pone de nuevo en marcha con el crecimiento demográfico y el declive progresivo de la extrema pobreza; sin olvidar el proceso de urbanización (p.37). No en vano, el avance técnico y el progreso social van demasiado de prisa para ciertos sectores de la población. "La secularización a marcha forzada, las reformas societales, la evolución de las costumbres [y] el torbellino tecnológico suscitan [reacciones de desaprobación en su seno]" (p.37).

Lo evidente es que el siglo XX nos ha hecho entrar en una nueva era marcada por una relación renovada con el tiempo, el "presentismo", en el cual, "mientras el futuro se considera como una amenaza, la Historia ha dejado de ser una guía [para convertirse en] un objeto destinado a confortar" (p.38). Según Tertrais, "la Tierra se uniformiza y la globalización de los intercambios, las grandes migraciones [y] la mezcla de las culturas [hacen desaparecer] los puntos de referencia. Estamos, [en ese sentido], en la era de la inseguridad cultural" (p.38). "La laicización, la urbanización y la industrialización han [desorientado] a los pueblos [y] el liberalismo ha mostrado sus límites" (p.39). En los países occidentales, nos dice el autor, los pueblos están atemorizados por la dilución religiosa, el mestizaje cultural y la desclasificación social (p.39). Además, "el yihadismo combatiente y el salafismo militar quieren socavar los fundamentos de estas sociedades" (p.139), lo que genera un agrio debate sobre el lugar del Islam que suscita numerosos temores.

Globalmente, las clases medias de estos países no se han beneficiado de la globalización y la mayoría de la población de los países occidentales ha dejado de reconocerse en el relativismo cultural, la promoción de la diversidad y de las minorías, y reivindica la vuelta a un relato nacional federador ( $\mathrm{p} .40)$ :

En Rusia, en Oriente Medio, en Asia, pero también en Estados Unidos y en Europa, la hora de la revuelta ha sonado. Es la venganza de los Estados que se [consideran] humillados y de los individuos que se sienten desclasificados (p.41).

Pero, sobre todo, existe "la tentación del retorno a los [orígenes], como antídoto al progreso y a la globalización. Es la era de la nostalgia (...). Es la edad de la reacción" (p.41). En ese sentido, "la revancha de la Historia es, en una amplia medida, un deseo de pasado" en el cual se busca una Historia de confort (p.42). "El pasado es erigido en refugio [y] se convierte en un mecanismo de defensa" (p.42). De hecho, "rehabilitar los relatos nacionales, [recuperar sus raíces, y] estar orgulloso de su pasado (...) constituye un fuerza, una fuente de unidad y de solidaridad" (p.42).

En ese sentido, la identidad de los Estados se construye hoy en día más a través del tiempo que del espacio, y más gracias a la Historia que a la geografía (p.43). Como lo subraya McMillan, la Historia se ha convertido en "más necesaria que en el pasado para asentar la legitimidad de las reivindicaciones territoriales" ${ }^{\text {. Ade- }}$ más, la proliferación de los Estados ha dado lugar a la necesidad de construir otras

5 M. MacMillan: Dangerous Games. The Uses and Abuses of History. New York: Modern Library, 2009, p.101. 
tantas historias nacionales, a menudo a partir del recuerdo de un héroe local o de símbolos de un pasado milenario (p.44). A su vez, "el crecimiento económico del inicio del siglo XXI ha permitido a [numerosos Estados] emerger o volver a [surgir]. Con, a menudo, un deseo de revancha sobre el colonialismo y el imperialismo" (p.44). Esto implica considerar que "la Historia es construida, imaginada, mitificada. La tradición es inventada. El pasado es recompuesto" (p.45). En ese sentido, "un pueblo que recupera el orgullo es a menudo (...) una nación cuyos dirigentes hacen todo lo posible para entregarse a las delicias de la exaltación del pasado a fin de que no mire demasiado el presente" (p.45).

Para concluir este capítulo, indica Tertrais que el periodo contemporáneo está dominado por ideologías religiosas y civiles que se inscriben en una herencia histórica (p.46). No obstante, la fuerza de lo religioso no concierne solamente la confesión musulmana sino que afecta igualmente el mundo occidental y cristiano (p.46). "El territorio y la frontera, el Estado y Dios [son los] marcadores de la contramodernidad" (p.46). Pero, esto no significa que la revancha de la Historia se reduzca a un simple deseo de retorno al pasado y a un rechazo de la modernidad, sino que trata, a menudo, de crear una nueva alianza entre tradición y modernidad (p.47).

En el tercer capítulo, que se interesa por las consecuencias de la Historia, el geo-politólogo galo reconoce que el llamamiento al pasado es una aspiración legítima e "indispensable a la estructuración de los individuos y a la cohesión de las naciones" ( $\mathrm{p}$.49). No en vano, subraya también que "la manipulación de la relación al pasado puede (...) ser fuente de patología colectiva, cuyos efectos [pueden ser] desastrosos" (p.49). De hecho, las analogías heroicas incendian las mentes, además de ser fuentes de ansiedad (p.49), lo que demuestra que "actuar, basándose en la fuerza de la analogía, puede (...) ser peligroso" (p.51). La manipulación de la Historia es más grave aún, al convertir los pueblos en ciegos, especialmente en los regímenes autoritarios (p.51). De manera más amplia, "en las relaciones internacionales, la movilización de la Historia enquista las crisis, porque eleva los retos y convierte los relatos nacionales en incompatibles" (pp.52-53). En ese sentido, "la herida histórica se convierte en un arma política" (p.53).

Para Tertrais, "de la construcción identitaria a través de la Historia a la creación de las figuras del enemigo hereditario y del chivo expiatorio, (...) solo hay un paso", sabiendo que "el mejor chivo expiatorio posible es la figura mítica del occidental, [considerado] en Rusia, Oriente Medio y Asia, como responsable de todos los males" (p.53). El occidental es criticado por su vinculación con el colonialismo, el imperialismo y la esclavitud, pero igualmente por su identificación con el liberalismo, el progresismo y el modernismo (pp.53-54). Más aún, el judío, o su encarnación simbólica contemporánea, el israelí, constituye el chivo expiatorio por excelencia (p.54). "La identificación de un chivo expiatorio permite una denegación de responsabilidad, mientras que el comportamiento victimario constituye una (...) estrategia de evitación" (p.54).

En ese sentido, la Historia puede convertirse en un componente tóxico que nutre el resentimiento. "Se convierte entonces en el caldo de cultivo del odio" (p.55). De hecho, "los focos de tensión que se han encendido estos últimos años hacen un llamamiento a referencias históricas que atizan las pasiones" (p.55). A menudo, se convoca un pasado glorioso y se reivindica la posesión de tierras ancestrales (p.55). 
Además, "la Historia es el perfecto justificante de [ambiciones] expansionistas o irredentistas. Para los nostálgicos del pasado, las fronteras (...) de los antiguos imperios siguen siendo visibles" (p.55). Así, la Rusia de Vladimir Putin extrae del pasado una triple legitimidad para actuar como lo hace en Ucrania. Alude, a la vez, a unos derechos históricos, a la existencia de un país como entidad separada y a la lucha contra el nazismo (p.56). Esto demuestra que, lo que está en juego en las grandes crisis, son menos cuestiones materiales, como aspectos simbólicos anclados en la Historia (p.56).

El autor observa que "la invocación de la Historia está particularmente presente en los pueblos separados" (p.57). Es una forma de "narcisismo de las pequeñas diferencias que está a la obra en la construcción de una identidad separada, e incluso opuesta a la de su vecino proveniente de la misma familia" (p.57). Cada país, nuevamente constituido, moviliza la Historia en beneficio de su propia causa (p.58). "En manos de emprendedores de la polarización, (...) estas divisiones, imaginarias o anodinas, son agudizadas, afinadas y se convierten en armas políticas" (p.58). Generan una guerra de las memorias que son a menudo unos conflictos de anterioridad (p.58). "Estas competencias memoriales pueden dificultar e incluso imposibilitar cualquier posibilidad de convivencia" (p.59). Y, en estas disputas sobre las herencias nacionales, "la arqueología se convierte en un deporte de combate político" (p.59).

En el último capítulo, que se interesa por el buen uso del pasado, Tertrais observa que, "más de veinticinco años después del final de la Guerra Fría (...), las pasiones ancladas en la Historia se han convertido y se afirman, cada vez más, como un resorte esencial de las relaciones de fuerza internacionales" (p.102). Ante ese desafío duradero, la prioridad consiste en conocer y en explicar. Esto implica desconfiar de las analogías, ya que la tendencia a buscar similitudes en la Historia es "un síntoma del estrecho 'presentismo' de una cultura occidental que solo puede ver en el pasado el reflejo infinito de sus propias preocupaciones, [en el marco de] una cultura obsesionada por los aniversarios y la memoria" (p.102). La lista de las analogías históricas "desplazadas o inapropiadas que [contaminan] los debates estratégicos contemporáneos es larga" (p.103). Las analogías solo son legítimas como instrumentos preventivos. Así, referirse a las guerras de Vietnam, Afganistán o Irak puede servir de advertencia (p.104). A su vez, "la analogía histórica sirve (...) [para] comprender la naturaleza humana, imaginar escenarios posibles [y] abrir la reflexión" (p.106).

Prosiguiendo su análisis, el geo-politólogo galo constata que,

Cuando un Estado es culpable de crímenes de masas, la catarsis, la justicia, el arrepentimiento y el recuerdo son, como mínimo, obligaciones morales hacia la memoria de los muertos y el sufrimiento de los supervivientes. Son igualmente necesarios al equilibrio de una nación (p.107).

Pero, cuando dos partes implicadas se han combatido, "el recuerdo y la reconciliación no son necesariamente compatibles" (p.107). Al contrario, "la reconciliación es difícil varias décadas después de un conflicto cuando los relatos de cada parte se 
han enquistado en las memorias nacionales" (p.108). De hecho, David Rieff ${ }^{6}$, habiendo constatado hasta qué punto la memoria histórica podía ser aplastante, subraya "las virtudes del olvido" (p.109), aunque no sea la panacea (p.110), o, al menos, la necesidad de encontrar el momento justo para recordar (p.110).

En cualquier caso, el conocimiento de un acontecimiento histórico no implica necesariamente el reconocimiento de su propia responsabilidad en su desenlace (p.112). Pero, incluso la práctica de la empatía hacia la otra parte no supone "considerar que todos los relatos históricos se equivalgan" (p.112). Esa comprensión es dificultada por la vigencia de los relatos nacionales. En efecto, como lo subraya Carla Hesse, "para existir, una [comunidad] necesita un relato nacional que reúna una idea de la temporalidad, pero también del espacio. (...) La historia patriótica es una fuerza de cohesión social" (p.113). Para Tertrais, esa historia es legitima a dos condiciones: por una parte, de no confundir el mito y la realidad, y de recordar que "el pasado está siempre compuesto" (p.113); y, por otra parte, de "no convertir el mito nacional en una reivindicación política" (p.115). En ese sentido, hoy en día, "el deber de la Historia es (...) más importante que el deber de la memoria, porque, tanto [las carencias] de la historia como los excesos de memoria, desembocan en una sociedad que se fragmenta [en torno al] pasado" (p.118).

Al término de la lectura de La revanche de l'Histoire, es obvio reconocer la pertinencia de la tesis defendida, es decir el retorno de la "gran historia" en las relaciones internacionales, y el interés de aplicar la perspectiva historiográfica al objeto geo-político. Ofrece una lectura sistematizada, gracias a una gran coherencia teórica, e ilustrada, gracias al perfecto dominio de la realidad internacional en su diversidad y complejidad. En ese sentido, se trata de una obra de madurez, fruto de varias décadas de reflexión e investigación. Todo ello, acompañado de un sentido de la fórmula, que le permite resumir en una frase una tesis esencial del libro, y de la fluidez de su estilo, que propicia la comprensión de su razonamiento. No en vano, Tertrais tiene una visión demasiado clásica de las relaciones internacionales y de la historia, donde prevalecen los Estados, los grandes acontecimientos y los personajes históricos. De hecho, se aleja de la historiografía contemporánea que incide en las mentalidades y sensibilidades, a pesar de que haga referencia a las obras de Pierre Hassner ${ }^{7}$ y Marc Ferro ${ }^{8}$ que subrayan la importancia de las pasiones y del resentimiento en los conflictos internacionales.

En cualquier caso, la lectura de esta obra, corta pero densa, y muy estimulante intelectualmente, se antoja imprescindible para mejorar nuestra compresión de la geopolítica contemporánea.

Eguzki Urteaga

Departamento de Sociología y Trabajo Social Facultad de Relaciones Laborales y Trabajo Social

Universidad del País Vasco

E-mail: eguzki.urteaga@ehu.eus

6 D. Rieff: In Praise of Forgetting. Historical Memory and Its Ironies. New Haven, Yale University Press, 2016.

P. Hassner (2005) "La revanche des passions". Commentaire, (110), 2005, 299-312.

8 M. Ferro: Le Ressentiment dans l'histoire. Comprendre notre temps. París, Odile Jacob, 2007. 